\title{
A Weighted Multiple Regression Model to Predict Rainfall Patterns: Principal Component Analysis approach
}

\author{
Retius Chifurira \\ School of Mathematics, Statistics and Computer Sciences, University of KwaZulu - Natal, \\ Private Bag X54001 Durban 4000, South Africa \\ Email: chifurira@gmail.com \\ Delson Chikobvu \\ Department of Mathematical Statistics and Actuarial Sciences, University of Free State, \\ P.O. Box 339 Bloemfontein 9300, South Africa \\ Email: chikobvu@ufs.ac.za
}

\section{Doi:10.5901/mjss.2014.v5n7p34}

\begin{abstract}
In this study, a multiple regression models developed to explain and predict mean annual rainfall in Zimbabwe. Principal component analysis is used to construct orthogonal climatic factors which influence rainfall patterns in Zimbabwe. The aim of the study is to develop a simple but reliable tool to predict annual rainfall one year in advance using Darwin Sea Level Pressure (Darwin SLP) value of a particular month and a component of Southern Oscillation Index (SOI) which is not explained by Darwin SLP. A weighted multiple regression approach is used to control for heteroscedasticity in the error terms. The model developed has a reasonable fit at the $5 \%$ statistical significance level can easily be used to predict mean annual rainfall at least a year in advance.
\end{abstract}

Keywords: Principal Component Analysis, multiple regression, Darwin Sea level Pressure, Southern Oscillation Index, previous year

\section{Introduction}

For many years the effect of global warming on food security, rainfall and temperature patterns has received great attention from policy makers and academics. Food insecurity is caused by many factors such as lack of proper planning, lack of appropriate farming methods and techniques, inadequate rainfall longer lead - time prediction models. In Southern Africa droughts occur more frequently affecting large numbers of people and causing tremendous economic losses, environmental damage and social hardships. Most countries in southern Africa depend on rain - fed agriculture which is the mainstay of the economies. The prime cause of drought is the occurrence of below normal precipitation, which is affected by various natural phenomena. Firstly, as noted by Panu and Sharma (2002), the most notable large scale climatic variation that occur from one year to another, is the Southern Oscillation climatic condition, which manifests itself in the differential oceanic temperature phenomenon across the tropical Pacific Ocean. The SOI is the difference between seasonally normalised sea level pressures of Darwin (in Australia) and Tahiti (in Mid Pacific). Secondly, Darwin Sea Level Pressures has been found to influence seasonal rainfall patterns in Zimbabwe (Manatsa et al., 2007).

Research has provided evidence of relationships among meteorological variables (Webster, 1981; Rocha, 1992; Ropelewski \& Halpert, 1987). Most researches on predictability of rainfall in Zimbabwe focussed on correlations between phases of SOI and rainfall (Matarira \& Unganai, 1994; Torrance, 1990; Waylen \& Henworth, 1995; Richard et al, 2000). Makarau \& Jury (1997) used a host of meteorological variables to predict summer rainfall in Zimbabwe. Manatsa et al (2007) used correlation analysis to identify the period lags for which SOI and Darwin pressure anomalies are significantly correlated with the Zimbabwean Summer Precipitation Index. The authors concluded that progressive lagged four months averaged Darwin pressure anomalies are correlated with the Zimbabwean Summer Precipitation Index. Ismail (1986) proposed an Empirical Rule from which the mean seasonal rainfall over Zimbabwe can be predicted three months before the start of the rainy season and ten months before its end using Southern Oscillation. The author concluded that the Southern Oscillation Index has an influence on the seasonal rainfall over Zimbabwe. The aim of this study is to develop a simple rainfall predictive model using climatic determinates such as Southern Oscillation Index (SOI) and Darwin Sea Level Pressures (Darwin SLP) for a country such as Zimbabwe, at least a year in advance. 


\section{The data}

\subsection{Zimbabwe's rainfall}

The historical annual mean rainfall data in Zimbabwe for the period years 1974 to 2009 was collected from the Zimbabwe Department of Meteorological Services. The mean annual rainfall values were calculated by averaging the monthly rainfall totals. The summer period stretches from October to March of each year.

Zimbabwe's main rains are associated with the behaviour of the Inter Tropical Convergence Zones (ITCZs), whose oscillatory behaviour is influenced by changing pressure patterns to the north and south of the country (Buckle, 1996).

Zimbabwe lies in the South West Indian Ocean zone that often is affected by tropical cyclones. Tropical cyclones are low pressure systems which, in the Southern hemisphere, have well- defined clockwise wind circulations spiralling towards the centre with great intensity. The strongest winds and heaviest rains occur in the region close to the centre. Cyclones that develop over the western side of the Indian Ocean occasionally have an impact on the rain season. The amount and intensity of rainfall during a given wet spell is enhanced by the passage of upper westerly waves of midlatitude origin (Smith, 1985; Buckle, 1996).

\subsection{Darwin Sea Level Pressure}

Sea Level Pressure is the atmospheric pressure at mean sea level either directly measured by stations at sea level or empirically determined when the station is not at sea level. The monthly Darwin SLP values were sourced from the internet website http://www.cpc.ncep.noaa.gov/data/indices/da. In this paper, the Darwin SLP values are not directly measured at Darwin but empirically determined using the reduction formula.

The manual of Barometer (1963) gives the equation for the reduction of a station pressure to Sea Level Pressure as:

$$
\begin{aligned}
& p_{0}=p \operatorname{Exp}\left[\frac{H K \ln (10)}{T_{m v}}\right] \\
& \text { Where: } \\
& p_{0} \text {-is the Sea Level Pressure }(m b) \text {. } \\
& p \text {-is the station pressure }(m b) \text {. } \\
& K \text { - Hypsometric constant }\left(0.00266895^{\circ} \mathrm{R} / \mathrm{m}\right) \text {. } \\
& H \text { - Station elevation (geo-potential meters } m \text { ). } \\
& T_{m v} \text { - Mean virtual temperature of the column of air between the station and sea level ( } \mathrm{R} \text { ). }
\end{aligned}
$$

\subsection{Southern Oscillation Index}

The SOI data is obtained from the Internet websitehttp://www.longpaddock.qld.gov.au. The SOI is calculated from the monthly or seasonal fluctuations in the air pressure difference of the area between Tahiti (in the mid-Pacific) and Darwin (in Australia). The SOI gives a simple measure of the strength and phase of the difference in sea-level pressure between Tahiti and Darwin. The difference is given in terms of an index. The SOI often range from about -35 to about +35 , and the value of the SOI can be quoted as a whole number. A strong and consistent negative SOI pattern is related to EINiño. Conversely, a deep and consistent positive SOI pattern is related to LaNiña. ElNiño (associated with negative SOI phases) is usually associated with below normal rainfall and LaNiña (associated with positive SOI phases) is associated with above normal rainfall. ElNiño is the abnormal warming in temperature of surface ocean waters in the eastern tropical Pacific Ocean. While, LaNiñais the cooling of surface ocean waters in the eastern tropical Pacific Ocean. The changes in temperature of the ocean waters affect surface air pressure in the Pacific Ocean, a phenomenon known as Southern Oscillation. Southern Oscillation is the see-saw pattern of reversing surface air pressure between the eastern and western tropical Pacific Ocean: when the surface pressure is high in the eastern tropical Pacific Ocean, it is low in the western tropical Pacific Ocean and vice versa.

\section{Methodology}

In this paper, dependent rainfall variable is expressed in terms of independent explanatory variables. Multiple linear regressions can be used to model a relationship between the dependent variable and the explanatory variables. It allows investigating the effect of changes in the various factors on the dependent variable. If the observations are measured 
over time, the model becomes a time series regression model. The resulting statistical relationship can be used to predict values of rainfall. To ascertain the predictive power of the model, all assumptions of multiple linear regression must be met.

\subsection{Multiple regression}

Probabilistic models that include more than one independent variables are called multiple regression. The model can be written as:

$$
y_{t}=\beta_{0}+\beta_{1} x_{1, t}+\beta_{2} x_{2, t}+\cdots+\beta_{p} x_{p, t}+N_{t}
$$

where $y_{t}$ is the $t^{t h}$ observation of the dependent variable, $x_{i, t}$ for $i=1,2, \ldots, p$ is the corresponding observation of the explanatory variable whose predictive influence is of interest. Parameters $\beta_{i}$ are unknown and the probabilistic component of the model $N_{t}$ is the unknown error term. The value of the coefficient $\beta_{i}$ determines the contribution of the independent variable $x_{i, t}$ given that the other independent variables are held constant. Using classical estimation techniques estimates for the unknown parameters are obtained. If the estimated values for $\beta_{0}, \beta_{1}, \beta_{2}, \ldots, \beta_{p}$ are given by $\hat{\beta}_{0}, \hat{\beta}_{1}, \hat{\beta}_{2}, \ldots, \hat{\beta}_{p}$, then the dependent variable is estimated as:

$\hat{y}_{t}=\hat{\beta}_{0}+\hat{\beta}_{1} x_{1, t}+\hat{\beta}_{2} x_{2, t}+\cdots+\hat{\beta}_{p} x_{p, t}$

and the estimate $\widehat{N}_{t}$ for the error term $N_{t}$ is determined as the difference between the observed and the predicted dependent variable; $\widehat{N}_{t}=y_{t}-\hat{y}_{t}$. In the theoretical model several assumptions are made about the explanatory variables and the error term.

Firstly there must be insignificant correlation between the explanatory variables. When the explanatory variables are correlated, multicollinearity problem exists. Using two or more correlated independent variables in a model will contribute to redundant information. The estimated parameters will be unstable and unreliable if highly correlated variables are used in the model as explanatory variables. In the study at hand, the predictive power of SOI and Darwin Sea Level Pressure at a maximum lag is important. SOI values are calculated using Darwin Sea Level Pressure values and thus high correlation is anticipated. Principal component analysis is used to produce orthogonal explanatory variables.

\subsection{Principal Component Analysis}

Principal component analysis is a technique used to combine highly correlated factors into principal components that are much less highly correlated with each other. This improves the efficiency of the model.

In this study, the predictive power of Darwin Sea Level Pressure values $\left(I_{1}\right)$ and SOI values $\left(I_{2}\right)$ is explored. Two new, uncorrelated factors, $I_{1}^{*}$ and $I_{2}^{*}$, can be constructed as follows:

Let $I_{1}^{*}=I_{1}$

Then, we carry out a linear regression analysis to determine the parameters $\gamma_{1}$ and $\gamma_{2}$ in the equation:

$I_{2}=\gamma_{1}+\gamma_{2} I_{1}^{*}+\varepsilon_{1}$

$\gamma_{1}$ and $\gamma_{2}$ are the intercept and slope parameters of the regression model respectively and $\varepsilon_{1}$ is the 'error' term, which by definition is independent of $I_{1}^{*}=I_{1}$.

We then set:

$I_{2}^{*}=\varepsilon_{1}=I_{2}-\left(\gamma_{1}+\gamma_{2} I_{1}^{*}\right)$

By construction $I_{2}^{*}$ is uncorrelated with Darwin Sea Level Pressure values $\left(I_{1}\right)$ since $I_{2}^{*}=\varepsilon_{1}$, the residual term in the equation. Changes in $I_{2}^{*}$ is interpreted as the change in the observed values of SOI $\left(I_{2}\right)$ that cannot be explained by the observed change in Darwin Sea Level Pressure values $\left(I_{1}\right) \cdot I_{2}^{*}$ in the rainfall model (equation 1 ) explains the component of rainfall that cannot be explained by the Darwin SLP.

Another assumption in the rainfall model (equation 1) is that the error terms should be uncorrelated and have constant variance over time. This assumption is likely to be violated in regression models with time series data. Autocorrelation (the error terms being correlated among themselves through time) leads to regression coefficients which are unbiased, inefficient and the standard errors are probably wrong making $t$ tests and $F$ tests unreliable. In a regression with auto-correlated errors, the errors will probably contain information that is not captured by the explanatory variables. The Durbin - Watson test is used to assess whether the residuals are significantly correlated. A Durbin Watson statistic of 2 indicates absence of autocorrelation. The ACF and PACF can also be used to detect autocorrelation among the residuals. 


\subsection{Weighted least squares regression}

The multiple least squares criterion weighs each observation equally in determining the estimates of the parameters. The procedure treats all of the data equally, giving less precise measured points more influence than they should have and gives highly precise points too little influence. The weighted least squares weighs some observations more heavily than others, giving each data point its proper amount of influence over the parameter estimates, and this maximizes the efficiency of parameter estimation. Weighted least square reflects the behaviour of the random errors in the model.

The model $y_{t}=\beta_{0}+\beta_{1} x_{1, t}+\beta_{2} x_{2, t}+N_{t}$

$$
\text { Let } \boldsymbol{Y}=\left[y_{1}, y_{2}, \ldots y_{t}\right]^{\prime}, \boldsymbol{\beta}=\left[\beta_{0}, \beta_{1}, \beta_{2}\right]^{\prime}, \boldsymbol{X}=\left[\begin{array}{ccc}
1 & x_{1,1} & x_{2,1} \\
\ldots & \ldots & \ldots . \\
1 & x_{1, t} & x_{2, t}
\end{array}\right] \text { and } \boldsymbol{N}=\left[N_{1}, N_{2} \ldots N_{t}\right]^{\prime} \text { then the same }
$$

model equation can be written as

$$
\boldsymbol{Y}=\boldsymbol{X} \boldsymbol{\beta}+\boldsymbol{N}
$$

Parameter estimates using ordinary least squares can be found as

$\widehat{\boldsymbol{\beta}}=\left(\boldsymbol{X}^{/} \boldsymbol{X}\right)^{-1}\left(\boldsymbol{X}^{/} \boldsymbol{Y}\right)=\left[\hat{\beta}_{0}, \hat{\beta}_{1}, \hat{\beta}_{2}\right]^{\prime}$. Errors.

To find the weighted least squares parameters of the weighted model, we minimise the Weighted Sum of Squared

$$
\begin{aligned}
& W S S E=\sum_{t=1}^{n} w_{t}\left(y_{t}-\hat{y}_{t}\right)^{2} \\
= & \sum_{t=1}^{n} w_{t}\left(y_{t}-\hat{\beta}_{0}-\hat{\beta}_{1} x_{1, t}-\hat{\beta}_{2} x_{2, t}\right)^{2}
\end{aligned}
$$

where $w_{t}>0$ is the weight assigned to the $t^{t h}$ observation. The weight $w_{t}$ can be the reciprocal of the variance of that observation's error term, $\sigma_{t}^{2}$, i.e.,

$$
w_{t}=\frac{1}{\sigma_{t}^{2}}
$$

Observations with larger error variances will receive less weight (and hence have less influence on the analysis) than observations with smaller error variances. The estimates are:

$$
\widehat{\boldsymbol{\beta}}=\left(\boldsymbol{X}^{/} \boldsymbol{W} \boldsymbol{X}\right)^{-1}\left(\boldsymbol{X}^{/} \boldsymbol{W} \boldsymbol{Y}\right)
$$

Where $\boldsymbol{W}=\left[w_{1}, w_{2}, \ldots w_{t}\right]$ is the weight vector.

The biggest disadvantage of weighted least squares is the fact that the theory behind this method is based on the assumption that the weights are known exactly. This is almost never the case in real applications where, instead, estimated weights are used (Carrol \& Ruppert, 1988).

\section{Results}

In this section the results of the weighted multiple regression are discussed.

\subsection{Relationships between Zimbabwe's mean annual rainfall with climatic determinants}

In this section the results of the ordinary and weighted multiple regression are discussed.The correlation between mean annual rainfall for Zimbabwe and Darwin SLPISOI values is discussed. This paper discusses the results of the correlation between mean annual rainfall and Darwin SLP/SOI values at a lag of at least one year.

\subsubsection{The Zimbabwean Mean Annual Rainfall Patterns}

Figure 1 shows the time series of the mean annual rainfall for Zimbabwe from 1974 to 2009. Mean annual rainfall data is calculated as the mean of October to September monthly rainfall totals. The year "1974" means mean annual rainfall for the months October 1973 to September 1974. The highest rainfall was received in 1974, while the lowest rainfall was received in 1992 (the worst drought in the given history of the country). 


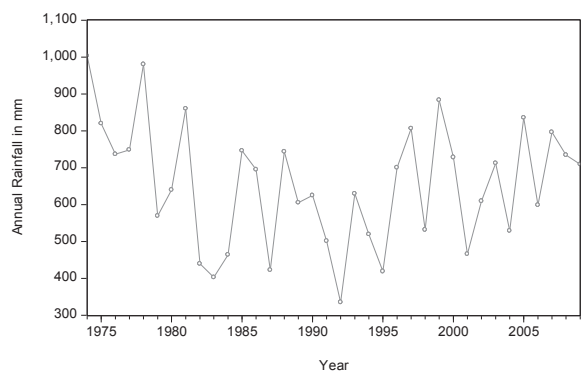

Figure 1: The Zimbabwean Mean Annual Rainfall for the period 1974 to 2009

\subsubsection{Darwin Sea Level Pressure}

The highest correlation between the monthly Darwin SLP and the Zimbabwean mean annual rainfall using the 1974 to 2009 rainfall data is -0.39 , using the March Darwin SLP value of the previous year. Zimbabwean mean annual rainfall has -0.38 correlation with Darwin SLP value for December of the previous year. The focus of this study is to determine a particular month's Darwin SLP which has a high correlation with mean annual rainfall at a lead time of a year or more. At a lead time of more than a year the correlations between the Darwin SLP and mean annual rainfall are insignificant. In this study Darwin SLP for March of the previous year will be used as explanatory variable.

\subsubsection{Southern Oscillation Index}

The Zimbabwean mean annual rainfall correlates positively with the Southern Oscillation Index for September of the previous year (Chikobvu and Chifurira, 2012). In this study SOI for September is be used as an explanatory variable in a regression model to construct orthogonal explanatory variables $I_{1}^{*}$ and $I_{2}^{*}$.

\subsection{Multiple regression}

Table 1 shows the results of the multiple regression approach to predict Zimbabwe's mean annual rainfall using the Darwin SLP for March at a lag of one year and the principal component of SOI for September of the same year which is not explained by Darwin SLP. The multiple regression model is:

$$
\hat{y}_{t}=\hat{\beta}_{0}+\hat{\beta}_{1} x_{1, t-1}+\hat{\beta}_{2} x_{2, t-1}
$$

where $\hat{y}_{t}$ is the predicted mean annual rainfall, $x_{1, t-1}$ is Darwin SLP value for March of the previous year and $x_{2, t-1}$ is $I_{2}^{*}$ the component of SOI for September of the previous year which is not explained by the corresponding Darwin SLP value for March.

Table 1: Multiple regression model for predicting mean annual rainfall

\begin{tabular}{|c|c|c|}
\hline Variable & coefficient & pvalue \\
\hline & $\hat{\beta}_{0}=995.1645$ & 0.0000 \\
Darwin $_{\text {marc }(-1)}$ & $\hat{\beta}_{1}=-43.324$ & 0.0162 \\
$I_{2}^{*}$ & $\hat{\beta}_{2}=4.5628$ & 0.0629 \\
\hline
\end{tabular}

From table 1 , the estimates of $\beta_{0}$ is 995.1645 ( $p$ value $\left.=0.0000<0.05\right), \beta_{1}$ is -43.324 ( $p$ value $=0.0162<$ 0.10 ) and $\beta_{2}$ is 4.5628 ( $p$ value $=0.0629<0.10$ ). The multiple regression model is significant at $10 \%$ level. The model has a multiple $R^{2}=0.24$. The Durbin - Watson statistic of $2.28>2$ indicates that the residuals are correlated. The model can be improved by incorporating the moving average errors to capture information contained in the residuals.

\subsubsection{Testing for normality of residuals}

Figure 2 shows the normal probability Q-Q plot of the residuals from the multiple regression model. 


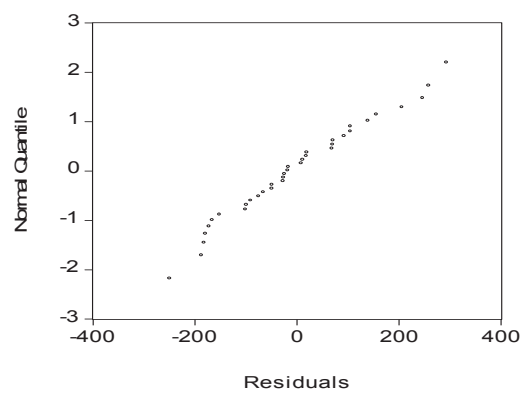

Figure 2: Normal Q-Q plot of residuals for multiple regression model

The normal Q-Q plot of the residuals is almost a straight line, suggesting that the residuals are normally distributed. Thus, the model does not seem to violate the normality assumptions significantly

\subsubsection{Testing for constant variance}

Figure 2 shows the scatter plot of residuals against predicted mean annual rainfall from the ordinary least squares regression model. The plot of residuals against predicted values indicates clustering, which suggests that the model violates the assumption of constant variance. This means that the model can be improved by stabilizing the variance using the weighted least squares method.

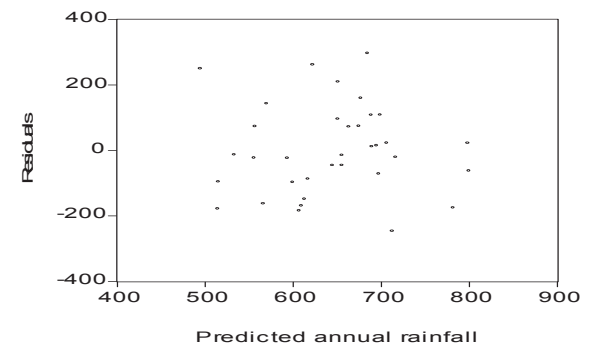

Figure 3: Residuals versus predicted values for multiple regression model

Figure 4 shows predicted and observed mean annual rainfall from 1974 to 2009 . The model fails to capture the variability in the observed values, and therefore, needs to be improved.

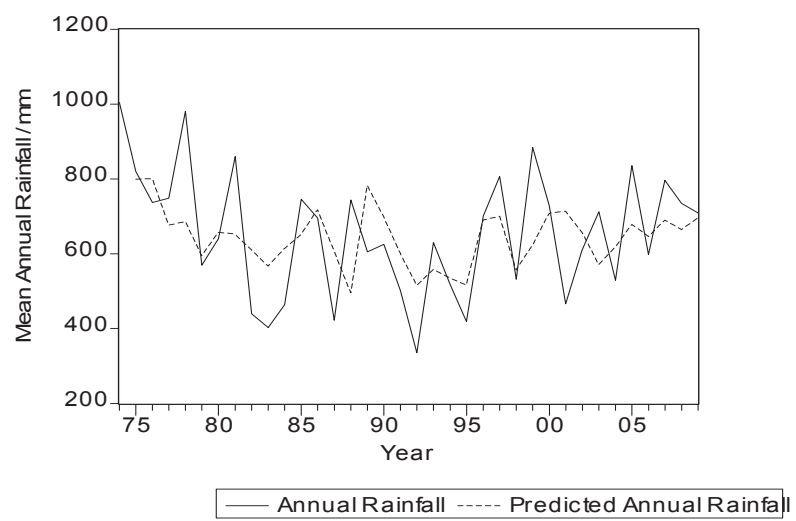

Figure 4. Observed rainfall versus predicted rainfall using multiple regression model 


\subsection{Weighted regression model}

To address the heteroscedacity in the data, weighted regression is used. Table 2 shows the weighted linear regression models results for rainfall $\hat{y}_{t}^{*}$ :

$$
\hat{y}_{t}^{*}=\hat{\beta}_{0}^{*}+\hat{\beta}_{1}^{*} x_{1, t-1}+\hat{\beta}_{2}^{*} x_{2, t-1}
$$

where $x_{1, t-1}$ is Darwin SLP values for March of the previous year and $x_{2, t-1}$ is $I_{2}^{*}$ the component of SOI for September which is not explained by Darwin SLP for March. Various weights are considered in arriving at estimates $\hat{\beta}_{0}^{*}, \hat{\beta}_{1}^{*}$ and $\hat{\beta}_{2}^{*}$ using weighted regression.

Table 2: Weighted regression models

\begin{tabular}{|c|c|c|c|c|c|}
\hline $\begin{array}{c}\text { Explanatory } \\
\text { variables }\end{array}$ & Weight & $\begin{array}{c}\text { Coefficients } \\
\hat{\beta}_{0}^{*} \\
\hat{\beta}_{1}^{*} \\
\hat{\beta}_{2}^{*}\end{array}$ & p value & AIC & BIC \\
\hline \multirow{4}{*}{$\begin{array}{c}\operatorname{Darw}_{\operatorname{mar}(-1)} \\
I_{2}^{*}\end{array}$} & Darw $_{\text {mar }}$ & $\begin{array}{c}1061.526 \\
-51.766 \\
6.149\end{array}$ & $\begin{array}{l}0.0000 \\
0.0692 \\
0.0158\end{array}$ & 12.866 & 12.999 \\
\hline & $\frac{1}{\sqrt{D a r w_{\text {mar }}}}$ & $\begin{array}{c}962.279 \\
-38.914 \\
3.961\end{array}$ & $\begin{array}{l}0.0000 \\
0.0255 \\
0.0994\end{array}$ & 12.798 & 12.931 \\
\hline & $\frac{1}{I_{2}^{* 2}}$ & $\begin{array}{c}837.047 \\
-27.243 \\
-14.689\end{array}$ & $\begin{array}{l}0.0000 \\
0.0086 \\
0.0000\end{array}$ & 13.126 & 13.259 \\
\hline & $\frac{1}{I_{2}^{* 3}}$ & $\begin{array}{c}730.603 \\
-13.261 \\
-18.120\end{array}$ & $\begin{array}{l}0.0000 \\
0.0131 \\
0.0000\end{array}$ & 11.915 & 12.048 \\
\hline
\end{tabular}

The model with $\frac{1}{I_{2}^{* 3}}$ as the variance stabilizing weight was selected, because it is the model with the least AIC and BIC. The model is significant at $5 \%$ significance level. The estimates of $\hat{\beta}_{0}^{*}, \widehat{\beta}_{1}^{*}$ and $\hat{\beta}_{2}^{*}$ are $730.603,-13.261$ and -18.120 respectively.

\subsubsection{Checking model assumptions}

The ACF and PACF correlogram (Appendix) shows that the residuals are independent. The Durbin-Watson statistic is 1.942, indicating that the residuals are independent.

\subsubsection{Testing for Constant variance}

Figure 5 below shows the scatter plot of residuals against predicted mean annual rainfall from the multiple regression.

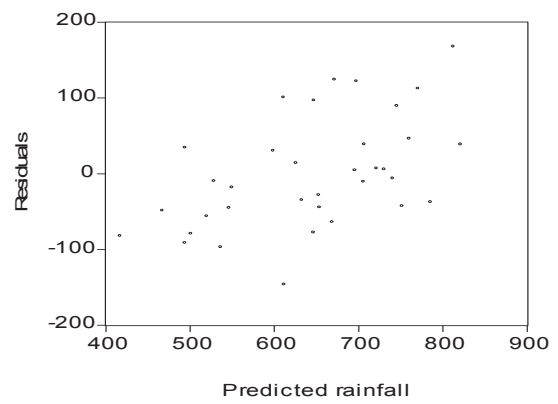

Figure 5: Residuals versus Predicted values for multiple regression 
From figure 5 the scatter plot does not show any clustering although they seem to show an upward trend. The model seems not to grossly violate the assumption of constant variance. It is important to check how the model performs in forecasting in-sample rainfall observations.

\subsubsection{Forecasting}

Figure 6 shows the observed mean annual rainfall against the predicted rainfall using weighted multiple regression.

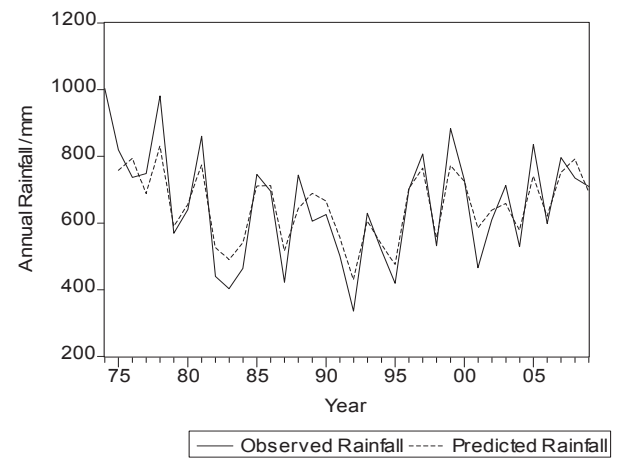

Figure 6: Rainfall versus Rainfall forecast

From figure 6 the model seems to be able to predict in - sample mean annual rainfall. The model shows little variability in between forecasts and actual rainfall. The model has a multiple $R^{2}=$. Thus, the model can be used to predict one year ahead mean annual rainfall for Zimbabwe. The out of sample forecasts will be done for the years 2010 to 2013.

\section{Summary}

In this study, weighted multiple regression models were developed to investigate the influence of the Darwin Sea Level Pressure and Southern Oscillation Index on the Zimbabwean mean annual rainfall patterns. Principal component analysis has been employed to construct orthogonal factors (non collinear variables). The combination of regression and time series analysis offers a powerful tool for predicting annual rainfall using Darwin SLP values and SOI values of a particular month with a lag of one year. Using Darwin SLP value for March and the component of SOI for September which is not explained by Darwin SLP for March, the mean annual rainfall for the year ahead can be predicted.

Regarding the data, it is clear that the explanatory variables incorporated in the model are limited. It would be interesting to include other climatic determinants such as Sea Surface Temperatures at Darwin for a particular month at a lag of one year and wind speed. However, the use of weighted regression gives an acceptable fit in the absence of these other factors. Extending the model with more factors may give a better understanding of the rainfall patterns in Zimbabwe. This is an area for further research.

\section{References}

Buckle, C. (1996). Weather and Climate in Africa. Longman: Harlow.

Carroll, R. J., \& D. Ruppert (1988). Transformation and Weighting in Regression. New York: Chapman and Hall.

Chikobvu, D., \& Chifurira, R. (2012). Predicting Zimbabwe's annual rainfall using the Southern Oscillation Index: weighted regression approach. African Statistical Journal, Volume 15 pp 87 - 107

Ismail, S. A. (1987). Long - Range seasonal rainfall forecast for Zimbabwe and its relation with $E l-N i \tilde{n} o /$ Southern Oscillation (ENSO). Theoretical and Applied Climatology Journal 38, 93 - 102

Makarau, A., \& Jury, M. R. (1997). Predictability of Zimbabwe Summer Rainfall. International Journal of Climatology 17: 1421 - 1432.

Manatsa, D., Chingombe, W., Matsikwa, H. \& Matarira, C. H. (2007). The superior influence of the Darwin Sea Level Pressure anomalies over ENSO as a single drought predictor in Southern Africa. Theoretical and Applied Climatology D01 10.1007/s00 704-0070315- 3.www.springerlink.com/index/8703666K421773hpdf

Manual of Barometry, (1963).Volume 1, 1st ed., U. S. Government Printing Office, Washington D. C.

Matarira, C. H., \& Unganai, L. S. (1994). A rainfall prediction scheme for southern Africa based on the southern oscillation. Technical report, SADC-REWU, Harare. 
Panu, U.S., \& Sharma, T.C. (2002). Challenges in drought research: some perspectives and future directions, Hydrological Sciences Journal 47(S).

Richard, Y., Trzaska, S., Roucou, P., \& Rouault, M. (2000). Modification of the southern African rainfall variability / ENSO relationship since the 1960s .Climate Dynamics 16: 883 - 895.

Rocha, A. M. C. (1992). The Influence of Global Sea Surface Temperatures on Southern African Summer Climate. Phd thesis, University of Melbourne: 249pp.

Ropelewki, C. F., \& Halpert, M. S. (1987). Global and regional scale precipitation patterns associated with the EINiño/Southern Oscillation. Mon Weather Review 115: 1606 - 1625.

Smith, S. V. (1985). Studies of the effects of cold fronts during the rainy season in Zimbabwe. Weather 40: 198 - 203.

Torrance, J. D. (1990). The Southern Oscillation and the rainy season in Zimbabwe. Zimbabwe Science News, $24: 4$ - 6.

Waylen, P and Henworth, P. (1996). A note on the timing of precipitation variability in Zimbabwe as related to the Southern Oscillation. International Journal of Climatology, 16:1137 - 1148.

Webster, P, J. (1981). Mechanism in determining the atmospheric response to sea level temperature anomalies. Journal of Atmospheric Science 38: $554-571$.

http://www.bom.gov.au/climate/current/soihtm1.shtml

http://www.cpc.ncep.noaa.gov/data/indices/da

\section{APPENDIX}

\section{ACF and PACF correlogram of square residuals for the weighted multiple regression model}

\begin{tabular}{|c|c|c|c|c|c|c|}
\hline Autocorrelation & Partial Correlation & & $A C$ & PAC & Q-Stat & Prob \\
\hline.$* *||$. & $.{ }^{* *} . \mid$ & 1 & -0.215 & -0.215 & 1.7634 & \\
\hline .1 .1 &.${ }^{*} .1$ & 2 & -0.012 & -0.061 & 1.7688 & 0.184 \\
\hline.${ }^{*} .1$ &.${ }^{*} .1$ & 3 & -0.087 & -0.108 & 2.0726 & 0.355 \\
\hline.$\left|{ }^{\star \star}.\right|$ & $.\left.\right|^{\star \star} . \mid$ & 4 & 0.261 & 0.231 & 4.9213 & 0.178 \\
\hline.${ }^{*} .1$ &.$||$. & 5 & -0.080 & 0.020 & 5.1969 & 0.268 \\
\hline$.\left.\right|^{*} . \mid$ & $.\left.\right|^{*} . \mid$ & 6 & 0.071 & 0.083 & 5.4238 & 0.366 \\
\hline$.{ }^{*} . \mid$ &.${ }^{*} .1$ & 7 & -0.188 & -0.145 & 7.0608 & 0.315 \\
\hline.${ }^{*} .1$ &.$* *||$. & 8 & -0.058 & -0.210 & 7.2231 & 0.406 \\
\hline .1 .1 & .1 .1 & 9 & 0.024 & -0.036 & 7.2515 & 0.510 \\
\hline .1 .1 & .1 .1 & 10 & 0.046 & -0.008 & 7.3618 & 0.600 \\
\hline.${ }^{*} .1$ & .1 .1 & 11 & -0.075 & 0.024 & 7.6641 & 0.662 \\
\hline.${ }^{*} .1$ & .1 .1 & 12 & -0.069 & -0.024 & 7.9315 & 0.719 \\
\hline .1 .1 &.$||$. & 13 & 0.032 & 0.015 & 7.9902 & 0.786 \\
\hline.$||$. & .1 .1 & 14 & 0.046 & 0.021 & 8.1180 & 0.836 \\
\hline$.{ }^{*} . \mid$ & $.{ }^{*} . \mid$ & 15 & -0.089 & -0.132 & 8.6342 & 0.854 \\
\hline.${ }^{*} .1$ &.${ }^{*} .1$ & 16 & -0.105 & -0.168 & 9.3895 & 0.856 \\
\hline
\end{tabular}

